\title{
IGUALDADE E DIFERENÇA NO EXERCÍCIO DA LIÇÃO NA ESCOLA
}

\author{
Gilberto Oliari ${ }^{1}$ \\ Elisete Medianeira Tomazetti ${ }^{2}$ \\ Jéssica Erd Ribas ${ }^{3}$ \\ Raquel Brum Sturza ${ }^{4}$
}

Resumo: No presente artigo reconhecemos a escola como um espaço em que a diversidade humana se encontra. Nosso objetivo é refletir sobre as relações de alteridade que podem se estabelecer no espaço escolar a partir dos conceitos arendtianos de igualdade e diferença. Relacionamos esses conceitos ao campo da responsabilidade docente pela garantia da renovação do mundo comum, que pode acontecer através da natalidade das crianças, adolescentes e jovens que fazem seu processo formativo na escola. Através de uma busca teórico - bibliográfica aponta-se a lição (leitura e comentário de textos) como uma possibilidade de aprendizagem e de exercício de reconhecimento da diversidade humana. Ao passo que a lição se produz em um espaço público de diálogos que possibilitam conhecer o Outro, podemos intuir que através dela é possível conhecer a si mesmo e construir novas formas de se relacionar e de conviver.

Palavras-chave: Educação. Alteridade. Lição. Renovação do Mundo. Prática Escolar.

\section{IGUALDAD Y DIFERENCIA EN EL EJERCICIO DE LA CLASE EN LA ESCUELA}

Resumen: En este artículo reconocemos a la escuela como un espacio en el que se encuentra la diversidad humana. Nuestro objetivo es reflexionar sobre las relaciones de alteridad que se pueden establecer en el espacio escolar a partir de los conceptos arendtianos de igualdad y diferencia. Relacionamos estos conceptos con el campo de la responsabilidad de la enseñanza para garantizar la renovación del mundo común, que puede suceder a través del nacimiento de niños, adolescentes y jóvenes que realizan su proceso formativo en la escuela. A través de una búsqueda teórico - bibliográfica, la lección (lectura y comentario de textos) se señala como una posibilidad de aprendizaje y ejercicio del reconocimiento de la diversidad humana. Si bien la lección tiene lugar en un espacio público de diálogos que permite conocer al Otro, podemos intuir que a través de él es posible conocerse a sí mismo y construir nuevas formas de relacionarse y vivir juntos.

Palabras clave: Educación. Alteridad. Lección. Renovación del mundo. Práctica escolar.

\footnotetext{
1 Doutorando em Educação pelo PPGE/UFSM. Mestre em Educação pelo PPGE/UNOCHAPECÓ. Licenciado em Filosofia e Ciências da Religião pela UNOCHAPECÓ. Bolsista Pós-Graduação FUMDES/UNIEDU. Professor da UNOCHAPECÓ e de Escola Pública da Rede Estadual de Santa Catarina. E-mail: gilba@unochapeco.edu.br

2 Doutora em Educação pela Universidade de São Paulo. Professora Titular da Universidade Federal de Santa Maria, Departamento de Metodologia do Ensino. E-mail: elisetem2@gmail.com.

${ }^{3}$ Doutoranda em Educação pelo PPGE/UFSM. Mestra em Educação pelo PPGE/UFSM. Licenciada em Filosofia. E-mail: erd.jessica@gmail.com.

${ }^{4}$ Doutoranda em Educação pelo PPGE/UFSM. Mestra em Educação pelo PPGE/UFSM. Especialista em Gestão Educacional pela UFSM. Licenciada em Filosofia pela UFSM. Bolsista de demanda Social da CAPES. E-mail: raquelsturza@hotmail.com.
} 


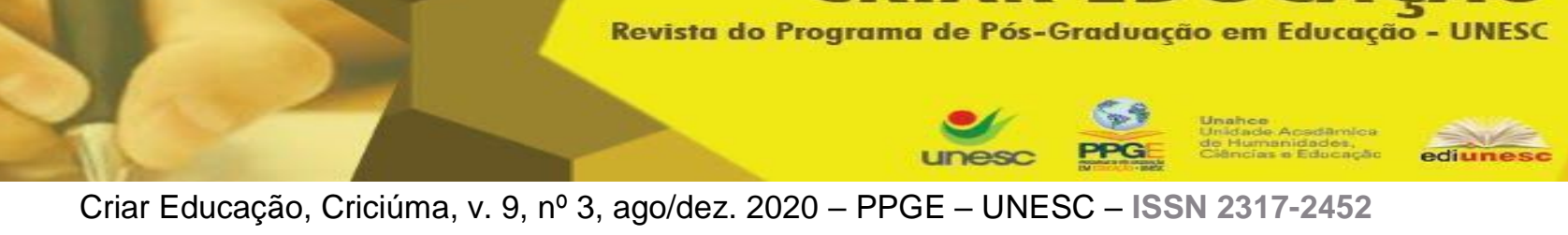

\section{Considerações iniciais}

A escola é um espaço heterogêneo. Nela diversos estudantes se encontram com pelo menos um objetivo em comum: aprender como o mundo funciona. Essa heterogeneidade se apresenta na diversidade de rostos, de modos de ser, de escrever e desenhar; nos diversos ritmos de aprender, nas diversas histórias de vida. No entanto, esses elementos tornam-se uma problemática quando professores e professoras, na relação pedagógica, assumem a tarefa de conduzir, mostrar ou apresentar à seus alunos o mundo do conhecimento.

Considerando a diversidade, cultural, econômica, étnica, de gerações, etc. que se encontra no espaço escolar, temos como objetivo, nesse texto, realizar uma reflexão sobre os conceitos de alteridade e responsabilidade a partir de Hannah Arendt $(2007,2008)$, relacionando-os com o exercício da lição, proposto por Jorge Larrosa (2016) na obra Pedagogia profana. Acionando tais conceitos intentamos pensar como um tipo específico de exercício pedagógico - a lição (LARROSA, 2016) - pode contribuir para que uma sala de aula e uma escola levem em consideração a heterogeneidade e a diferença.

Para avançarmos em nossas reflexões uma pergunta inicial torna-se indispensável, a saber: afinal de contas, o que é a escola? Embora todos tenhamos que passar anos de nossas vidas nesse espaço, sempre é válido conceituá-la para recuperar seu significado no processo formação e inserção dos novos que chegam ao mundo que nos é comum. Segundo Arendt (2004), "[...] para a própria criança a escola é o primeiro lugar fora de casa em que ela estabelece contato com o mundo público que a rodeia e a sua família" (p.280), esse espaço público é social e não político ${ }^{5}$, é um espaço de relações, de formação e de aprendizado. Desse modo, é possível afirmar que é papel da escola apresentar para crianças, adolescentes e jovens como o mundo é, quais relações são possíveis de se estabelecer nele e como ele funciona, tanto no âmbito natural/físico como nas relações sociais?

\footnotetext{
${ }^{5} \mathrm{O}$ mundo político para Arendt (2007) é o mundo dos adultos, o espaço onde se tomam as decisões acerca da vida pública dos cidadãos que habitam a mesma cidade. Esse ideário arendtiano está ligado a noção de política da Grécia Antiga onde os cidadãos (homens livres e maiores de idade) exerciam a política da polis na ágora. Para Arendt (2007) o espaço político é o espaço das decisões, e a escola é pode ser o espaço que prepara os sujeitos para atuarem no campo da política, por isso a escola é um espaço social.
} 
$\mathrm{Na}$ escola, de modo geral (pública e privada), acontecem relações entre pessoas que partilham de um fio comum que liga a todos/as sem distinção de etnia, cultura, religião, classe social/econômica; que possuem linguagens e modos de pensar semelhantes e partilham de anseios semelhantes. Mas nela também acontecem relações pedagógicas, que se referem aos processos de ensino e aprendizado dos conhecimentos construídos pela humanidade e que estão disponíveis para serem ressignificados, repensados e (re)atualizados pelas novas gerações.

Tais relações necessitam ser pautadas pelo princípio da alteridade, dada a heterogeneidade da escola. Alteridade consiste, em parte, na responsabilidade pelo mundo que os/as professores/as precisam assumir para legitimar sua autoridade (ARENDT, 2008). A responsabilidade, por sua vez, traduz-se no reconhecimento do Outro, estudantes, disponibilizando a ele conhecimentos, saberes e experiências que the tornem possível o conhecimento do mundo. Há, assim, uma abertura imanente que possibilita que as novas gerações possam vir a mudar esse mundo de maneira imprevisível.

De acordo com os pensadores belgas Masschelein e Simons (2017) - que têm construído reflexões no intuito de defender a escola como uma questão pública - o espaço escolar é "o lugar onde os jovens são abastecidos com tudo o que eles devem aprender para encontrar o seu lugar no mundo" (p.25). Eles, corroboram, dessa forma, com a perspectiva arendtiana de que a escola visa preparar os recémchegados ao mundo, ensinando-os sobre como ele é, ao mesmo tempo em que abre espaço para que cada um e cada uma encontre o seu modo de inserção nesse mundo.

As maneiras de realizar a ação pedagógica, responsável e comprometida com o mundo comum, são variadas; todavia, queremos destacar o exercício da lição como um caminho possível. Larrosa (2016) pensa a lição como um exercício de leitura do mundo, mediado pelo/a professor/a - "a ação de ler extravasa o texto e o abre para o infinito" (p.142). Praticar a lição é conhecer o mundo e vislumbrar possibilidades de inserção nele. 


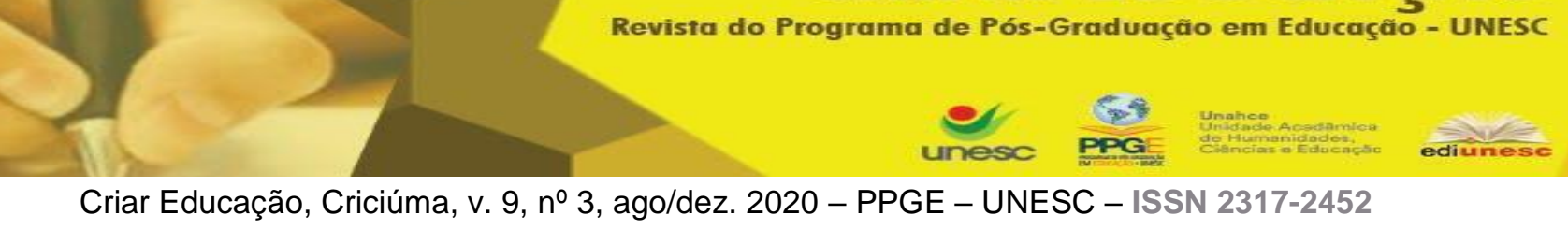

Alteridade e escola: sobre o praticar a lição

De acordo com a pensadora alemã. Hannah Arendt (2008), a condição humana pode ser distinguida em três atividades: o labor (processo biológico); o trabalho (artificialismo da existência humana - fabricação) e, a ação (política). Tomando como foco de reflexão, neste trabalho, as relações estabelecidas entre as pessoas, destacamos que a ação humana é a "única atividade que se exerce diretamente entre os homens, sem a mediação das coisas ou da matéria, corresponde à condição humana da pluralidade ao fato de que os homens, e não o Homem, vivem na Terra e habitam o mundo" (ARENDT, 2008, p. 15). A ação é atividade que acontece entre as pessoas, destacando assim os distintos modos de ser, pensar e conhecer existentes em uma sala de aula e na escola de modo amplo.

Quando tratamos de educação, estamos tratando de uma atividade que necessariamente acontece numa relação entre seres humanos. Seja entre o/a professor/a que ensina e o/a aluno/a que busca aprender, seja entre os/as estudantes entre si, seja entre professores/as, enfim, há um vasto conjunto de relações que ocorrem pelos processos de ensino, na escola. Para Arendt, (2007), a educação é uma das atividades mais elementares e necessárias da sociedade humana. Considerando que a sociedade não é estática, pois renova-se sempre com a chegada de novos sujeitos, cada criança recém-chegada apresenta-se num duplo sentido para o/a professor/a e para a escola, uma vez que "[...] é nova em um mundo que the é estranho e se encontra em processo de formação; é um novo ser humano e é um ser humano em formação" (ARENDT, 2007, p. 235). Ou seja, cada estudante ao chegar à escola é um novo ser que chega ao mundo e que se encontra em processo de formação, cada um com suas peculiaridades e formas de aprender. Sendo assim, caberá aos/as professores/as conduzir ${ }^{6}$ esses seres em formação ao mundo já existente e possibilitar nele sejam inseridos, trazendo a novidade de sua natalidade.

\footnotetext{
${ }^{6}$ O termo conduzir (advindo do conceito de condução) é empregado no texto como modo de pensar que o professor exerce uma ação pedagógica, a qual pode ser compreendida como o ato de levar, apresentar, instruir os alunos acerca de como o mundo social, político, histórico, natural, etc. funcionam. Segue-se assim a corrente de pensamento arendtiano que afirma que o papel da educação é conduzir os recém-chegados pelo mundo comum, tomando o cuidado para este mundo chegue com fruição às crianças adolescentes e jovens que vem ao mundo (ARENDT, 2007).
} 
Para que possamos abordar o tema das relações de alteridade é necessário dar um passo atrás e compreender como Arendt (2008) descreve o processo da aparição da identidade dos sujeitos no meio social. Para a autora, essa revelação acontece através do discurso e da ação em meio à pluralidade humana. Primeiramente é preciso apontar que essa pluralidade possui um duplo sentido: de igualdade e de diferença. O sentido da igualdade é de nos aproximar; possibilita que nos reconheçamos, pois, como diz a filósofa "se não fossem iguais, os homens seriam incapazes de compreender-se entre si e aos seus ancestrais, ou de fazer planos para o futuro e prever as necessidades das gerações vindouras" (ARENDT, 2008, p. 188). Diante da pluralidade dos seres humanos, há um sentido de igualdade que se manifesta na forma de falar e de se expressar, bem como, no modo de pensar e de construir conhecimentos e saberes.

$\mathrm{Na}$ escola, portanto, precisamos atentar para a dupla função igualdadediferença, antes de lançar mão de uma ou outra. Embora os/as alunos/as tenham diferentes ritmos de aprendizagem ou diferentes referenciais para alicerçar suas vidas, todos podem, potencialmente, ser iguais em capacidade de aprender. Paradoxalmente, é essa noção primeira de igualdade que permite a abertura para a compreensão da diferença. Nesse sentido "[...] a escola e os professores proporcionam um benefício [...] coloca todos numa posição inicial igual e fornece a todos a oportunidade de começar" (MASSCHELEIN, SIMONS, 2017, p. 15). A escola, pois, é o campo social que pode possibilitar a todos/as a oportunidade do começo, de iniciar-se no mundo e isso não ocorre de forma fechada, mas sim por meio de uma abertura, de uma fruição, na qual cada um/a possa estar e viver em sua diferença.

O segundo sentido da pluralidade humana, apontado por Arendt (2008) refere-se, justamente, à diferença existente entre os seres humanos. Segundo a pensadora, é o aspecto da diferença que nos diferencia de outros seres e aponta para a necessidade da revelação da identidade.

Se não fossem diferentes, se cada ser humano não diferisse de todos os que existiram, existem ou virão a existir, os homens não precisariam do discurso ou da ação para se fazerem entender. Com simples sinais e sons, poderiam comunicar suas necessidades imediatas e idênticas (ARENDT, 2008, p. 188). 
Se todos fossem iguais não haveria necessidade de expressar a identidade através do discurso. Todos teriam o mesmo percurso histórico, a mesma forma de perceber a vida, a mesma ética e a mesma moral. Contudo, parece ser o caso de que o mundo não se constitui de pura igualdade, nem mesmo de pura diferença, ele está articulado no par igualdade-diferença, que forja diversos seres humanos, que são únicos e partilham de uma pluralidade que os une. Prova disso são os inúmeros caminhos e percursos trilhados ao longo do tempo. Ninguém é necessariamente igual a outro ser, no entanto, há um princípio de igualdade que nos une na capacidade de nos compreendermos. Por isso, no processo de ensino, desenvolvido no espaço escolar, é necessário se perceber que "[...] cada aluno, independentemente de antecedentes ou talento natural, tem a capacidade de se tornar interessado em alguma coisa e se desenvolver de maneira significativa" (MASSCHELEIN, SIMONS, 2017, p. 72).

A partir da leitura de Hannah Arendt podemos pensar que educação tem a tarefa de oferecer a todos os recém-chegados ao mundo a mesma oportunidade de conhecê-lo. A escola se caracterizaria como uma espécie "[...] de vácuo no qual é dado tempo aos jovens e aos alunos para praticarem e se desenvolverem" (MASSCHELEIN, SIMONS, 2017, p. 73); é um local onde seria possível testar, experimentar, acertar e errar - dada as condições que oferece para suspender e profanar o mundo. Como uma instituição que se estabelece 'entre' o mundo público (sociedade) e o mundo privado (família), permite empreender essas duas ações: suspensão temporária e profanação. Suspender temporariamente o mundo significa criar tempo-livre para conhecê-lo, investigá-lo, pensá-lo e problematizá-lo. A partir da suspensão - epoché - abre-se, então, a possibilidade de profanação do mundo, isto é, a possibilidade de mudá-lo de forma imprevisível.

É nesse sentido que a lição pode ser entendida como um exercício de formação dos/as estudantes para criarem seu modo de ser e agir no mundo comum. Compreendemos, portanto, que "uma lição é uma leitura e, ao mesmo tempo, uma convocação à leitura, uma chamada à leitura. Uma lição é a leitura e o comentário público de um texto cuja função é abrir o texto a uma leitura comum" (LARROSA, 
Criar Educação, Criciúma, v. 9, № 3, ago/dez. 2020 - PPGE - UNESC - ISSN 2317-2452

2016, p. 139). O exercício da lição é um ato público, onde há leitura e comentário há a colocação de interpretações e de pontos de vista.

A experiência da lição no espaço escolar comum pode ser compreendida como movimento duplo de singularidade e pluralidade; ela estabelece uma aproximação. Assim "[...] com essa curiosa relação de alguém consigo mesmo, à qual chamamos de liberdade, e com a experiência da amizade, com essa curiosa forma de comunhão com os outros que chamamos de amizade" (LARROSA, 2016, p. 139). É, portanto, através da lição que temos uma das muitas possibilidades de perceber o duplo sentido da pluralidade. Quando há o exercício da leitura é possível reconhecer os aspectos de igualdade que unem a humanidade: a busca por perceber aquilo que é comum estabelece uma relação comigo mesmo, de modo que posso perceber que o que é comum a mim pode ser comum também ao Outro. Mas há, também, a dimensão da diferença que se manifesta, pois no comentário público estabelecemos relações com o Outro, percebendo que esse Outro também pode ter um posicionamento e em comunhão pode ser estabelecer uma relação de amizade.

A condição humana para pode ser paradoxal, pois caminha entre a singularidade e a pluralidade, "[...] a alteridade que o ser humano tem em comum com tudo o que existe, e a distinção, que ele partilha com tudo o que vive, tornam-se singularidade, e a pluralidade humana é a paradoxal pluralidade de seres singulares" (ARENDT, 2008, p. 189). Desse modo, parece ser possível afirmar que o mundo, que é povoado por seres singulares, que possuem características próprias é, ao mesmo tempo, um mundo plural no qual os sujeitos podem partilhar suas experiências e expectativas com outros seres singulares.

Trazemos para discussão o trecho de uma música composta por dois atores da telenovela vespertina da Rede Globo de Comunicação - Malhação (temporada: Viva a diferença), veiculada em rede nacional no dia 27/09/2017 (e, retransmitida no ano de 2020). A música é intitulada como Igual, diferente, igual, diferente, igual ${ }^{7} \mathrm{e}$ traz em sua letra, o seguinte conteúdo:

\footnotetext{
7 Letra de Bruno Gadiol. Interpretada por Guto e Benê - Malhação "Viva a diferença". Disponível: https://www.youtube.com/watch?v=ExPdCADFcgM acesso em 27 de jul. 2020.
} 
Se sou estranha ou esquisita, o que será?/ Sou igual, sou diferente/ E você como se sente?/ Sou diferente, não sei mentir/ Sou diferente, não sei como agir/ Se fosse um canário, seria um bem-te-vi/ Se fosse Beethoven, seria um colibri. Igual, diferente, igual, diferente, igual, diferente, igual.

Esse trecho da música nos faz pensar sobre o paradoxo singularidade $\mathrm{e}$ pluralidade arendtiano, pois procura dar ênfase ao sentimento de ser diferente de outros (que podem parecer ser iguais) e ao mesmo tempo apresenta a dificuldade de encontrar e expressar a própria singularidade do sujeito que se apresenta.

Essa música foi cantada por uma personagem da telenovela que sofreu bullying ao longo de sua vida estudantil; por ser muito sincera a personagem tinha sérias dificuldades de se relacionar com outras pessoas e de expressar suas emoções. Essa característica fazia com que seus colegas de aula fizessem piadas sobre o seu jeito de ser; muitos dela se afastaram, pois ela era considerada a diferentona da escola. Essa personagem expôs um problema: como possibilitar que as diferentes identidades se exponham no ambiente escolar sem que sejam capturadas pelos preconceitos?

Conhecer o mundo e instruir os recém-chegados nele, não pode ter como pretensão igualar ou massificar, pois cada um possui as suas características e,

[...] quanto mais iguais as pessoas se tornam em todos os aspectos, e quanto mais igualdade permeia toda a textura da sociedade, mais as diferenças provocarão ressentimento, mais evidentes se tornarão aqueles que são visivelmente e por natureza diferentes dos outros (ARENDT, 2004, p. 268).

Sendo assim prestar atenção às diferenças e trazê-las para o debate na escola, faz parte da responsabilidade docente de apresentar o mundo e possibilitar o surgimento do novo através do debate (diálogo) entre todos, com suas diferenças. Acreditamos que esse problema pode ser pensado com o conceito de natalidade de Arendt (2008). De acordo com a pensadora "[...] é com palavras e atos que nos inserimos no mundo humano; e esta inserção é como um segundo nascimento, no qual confirmamos e assumimos o fato original e singular do nosso aparecimento físico original" (ARENDT, 2008, p. 189). A natalidade, segundo nascimento, pode ser entendida como o fato de um sujeito tomar posição de suas características e pensamentos próprios e apresentar-se discursivamente para o mundo. É o que a personagem da telenovela faz ao cantar a música, descrita acima, para o coletivo de 
estudantes da escola, apresentando a sua posição em relação ao seu contexto de vida, aquilo que pode ser considerado a natalidade da personagem.

A natalidade traz consigo a possibilidade de uma novidade, pois trata do início de alguém, da exposição de uma identidade ao mundo. Segundo Arendt (2008) á através das ações e dos discursos que as possam apresentam suas identidades, seu modo de pensar e conhecer o mundo. Ao revelar a identidade inicia-se um processo de instauração de algo novo:

O novo sempre acontece à revelia da esmagadora força das leis estatísticas e de sua probabilidade que, para fins práticos e cotidianos, equivale a certeza; assim o novo sempre surge sob o disfarce do milagre. $O$ fato de que o homem é capaz de agir significa que se pode esperar dele o inesperado, que ele é capaz de realizar infinitamente o improvável. $E$ isto, por sua vez, só é possível porque cada homem é singular, de sorte que, a cada nascimento, vem ao mundo algo singularmente novo. Desse alguém que é singular pode-se dizer, com certeza, que antes dele não havia ninguém (ARENDT, 2008, p. 191).

Cada ser humano é singular; cada um produz o inesperado. A natalidade pode acontecer durante o processo de formação, na escola. Assim como o trecho da música aborda que cada um tem uma forma de encontrar-se no mundo, cada identidade se revela em um mundo estranho/novo e busca seu espaço para revelarse/inserir-se nele. O cuidado com o processo de formação desse novo ser humano é fundamental para que haja fruição deste em relação ao mundo como ele é, e que ao mesmo tempo seja possível que ele encontre seu espaço de inserção, de novidade.

Como saber se de fato está surgindo algo novo e valorizá-lo em vez de interditá-lo? Acreditamos que a lição pode ser um modo de criar possibilidades para esse nascimento. Tal afirmação se afirma no que nos diz Larrossa, (2016, p. 41): na lição "[...] os alunos são convocados a um texto, chamados a um texto. Através desta convocação, os alunos são situados no que se vem dizendo, nesse vir presente na leitura do que já se disse, nessa presença do já dito". A leitura da lição possibilita um situar-se no tempo, naquilo que já foi produzido. De certo modo, a lição possibilita recolher aquilo que foi dito, para que se possa dizer novamente e, além disso, se possa acrescentar algo novo, impensado, imprevisto, impossível de racionalização imediata. 
Desse modo, a lição pode apresentar uma possibilidade de novidade, pois "[...] na leitura da lição não se busca o que o texto sabe, mas o que o texto pensa. Ou seja, o que o texto leva a pensar" (LARROSA, 2016, p.141), o importante da lição é perceber que ela nos faz pensar, entrar nesse movimento do pensamento.

\begin{abstract}
O objetivo da lição não é nos deixar terminados pela assimilação do dito, nem nos deixar determinados pela aprendizagem dogmática do que deve ser dito, mas in-de-terminar aquilo que dá o que dizer, aquilo que fica por dizer. In-de-terminar é não terminar e não de-terminar. Por isso, ler é recolher-se na indeterminação do dizer: que não haja um final nem uma lei para o dizer, que o dizer não se acabe nem se determine. (LARROSA, 2016, p. 142).
\end{abstract}

Sendo assim, a leitura não encerra uma problemática, pelo contrário ela reabre novos posicionamentos, novas discussões e até postula a proposição de novas soluções aos problemas emergentes de nosso tempo. A lição abre a possibilidade da natalidade do sujeito que busca inserir-se em um mundo que é forjados em processos históricos, anteriores a nossa chegada. O exercício da lição não pode ser determinístico ou fechado em um círculo conceitual sistemático, sem o estabelecimento de relações; ele precisa abrir-se e possibilitar que a partir daquilo que já foi produzido se possam pensar novos pensamentos.

Vale destacar que "[...] a revelação da identidade através do discurso e o estabelecimento de um novo início através da ação incidem sempre em uma teia já existente, e nela imprimem suas consequências" (ARENDT, 2008, p. 196). A revelação de identidade, que é singular, encontra um espaço que é plural, onde outros seres humanos também estão fazendo a sua revelação. Desse modo a natalidade, entendida como revelação de identidade, nunca se restringe a duas pessoas.

Como a ação atua sobre seres que também são capazes de agir, a reação, além de ser uma resposta, é sempre uma nova ação com poder próprio de atingir e afetar os outros. Assim, a ação e a reação, jamais se restringem, entre os homens, a um círculo fechado, e jamais podemos, com segurança, limitá-los a dois parceiros (ARENDT, 2008, p. 203).

Posicionar-se no mundo e revelar sua identidade requer a compreensão de que fazemos parte de uma teia, na qual aquilo que um sujeito expressa chega a 
outros sujeitos e pode retornar de outro modo. Na escola essa teia é composta por diferentes sujeitos - professores/as, alunos/as, funcionários/as, comunidade escolar em geral - e cada um deles e cada uma delas compõe esse conjunto singular e heterogêneo de pessoas, posicionam-se em relação ao mundo, no entanto, caberá ao professor e à professora a responsabilidade de abrir espaço para todos/as, garantindo que possam estar em sua singularidade.

\section{Responsabilidade e alteridade: a lição na amizade}

$\mathrm{Na}$ escola professores/as têm a responsabilidade de conduzir alunos e alunas a empenharem-se em algo, estudar com afinco e perceberem que são capazes de iniciar algo novo no mundo. Nesse sentido, pode-se afirmar que

[...] a educação é a concessão de autoridade para o mundo, não só por falar sobre o mundo, mas também e, sobretudo por dialogar (encontrar, comprometer-se) com ele. [...] a tarefa da educação é garantir que o mundo fale com os jovens (MASSCHELEIN, SIMONS, 2017, p. 98).

As coisas do mundo podem chamar atenção, devem estar presentes na aula para que possam ser compreendidas e assumidas. Em outras palavras, o conhecimento produzido e apresentado na escola deve despertar uma responsabilidade naqueles que o aprenderam, que receberam os saberes, e nesse compromisso, pode despertar-se a renovação do mundo.

Segundo Emmanuel Lévinas (2011), filósofo lituano naturalizado francês, a necessidade ética está acima de qualquer explicação dos fenômenos, uma vez que, "[...] saber ou ter consciência é ter tempo para evitar e prevenir a inumanidade" (p.21). De acordo com o filósofo, pode-se afirmar que a relação pedagógica estabelecida entre professor/a e aluno/a na escola tem como pano de fundo a responsabilidade pelo cuidado com os princípios de igualdade e diferença presente em cada ser humano. Prevenir a inumanidade pode ser considerado como o desenvolvimento do reconhecimento da alteridade, a qual poderá despertar a necessidade de conhecer outras coisas quebrando o círculo fechado de opiniões.

Há que se compreender que o professor/a, na sala de aula, assume, por assim dizer, um papel de representante do mundo adulto, do mundo já constituído 
Criar Educação, Criciúma, v. 9, oㅡ 3, ago/dez. 2020 - PPGE - UNESC - ISSN 2317-2452

que aí está e que permanece em constante processo de mudança. Por isso, docentes são, em alguma medida, responsáveis pela proposição da lição; tem autoridade ${ }^{8}$ para apresentar os acontecimentos, objetos e fenômenos do mundo e desenvolver suas aulas a partir desses. É possível, ainda, afirmar com Arendt (2007), que "[...] a qualificação do professor consiste em conhecer o mundo e ser capaz de instruir os outros acerca deste, porém sua autoridade se assenta na responsabilidade que ele assume por este mundo" (p. 239). O/A professor/a, munido/a de conhecimentos sobre o mundo, instrui os recém-chegados, ao mesmo tempo em que assume responsabilidade pelo mundo que está apresentando, com vistas a sua renovação e impedindo sua destruição.

Para Arendt (2004) "[...] a razão é que toda criança procura instintivamente as autoridades para guiá-las nesse mundo em que ela é ainda uma estranha, em que não pode se orientar pelo próprio julgamento" (p. 281). Tal afirmação chama atenção para o fato de que o/a professor/a precisa estar atento/a e preparado/a para lidar com as diversidades presentes no mundo, a fim de instruir as crianças e jovens a terem responsabilidade pela humanidade - dessa maneira se dá a prevenção da inumanidade.

Detemo-nos por um momento no conceito de mundo. O mundo poderia ser compreendido como espaço geográfico que habitamos e lugar de onde retiramos nossa subsistência. Mas o mundo é muito mais: é, também, onde estabelecemos relações plurais, a partir das singularidades de cada sujeito. Desse modo, não cabe ao/a professor/a ensinar apenas como o mundo natural (físico, químico, biológico) e histórico funciona, mas também como se organiza o mundo social, o mundo de relações de alteridade. Expor esse mundo, de modo a suspendê-lo e profaná-lo, é um movimento complexo, pois as crianças e jovens podem se sentir perdidos.

A seguir, acionamos a continuação da música citada anteriormente:

Fico triste, tento me encaixar/ astronauta sem foguete/ navio perdido no mar/ peixe fora d'água/ fico sem ar/ estrada esburacada/ tem que ir devagar/ [...] mas já percebi/ você já não me engana/ quem nunca se sentiu assim?/

\footnotetext{
8 "[...] a autoridade no sentido mais lato sempre fora aceita como uma necessidade natural, requeridade obviamente tanto por necessidades naturais, o desamparo da criança, como por necessidade política, a continuidadede uma civilização estabelecida que somente pode ser garantida se os que são recém-chegados por nascimento forem guiados através de um mundo preestabelecido no qual nasceram como estrangeiros" (ARENDT, 2007, p. 128).
} 


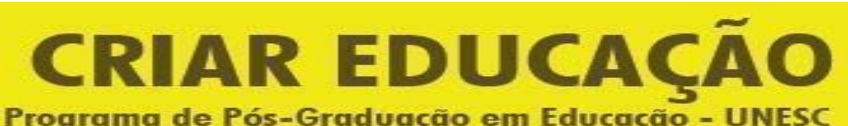

Revista do Programa de Pós-Graduação em Educação - UNESC

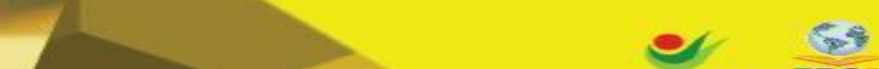

unesc PPG

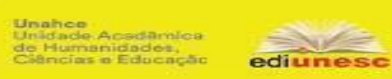

Criar Educação, Criciúma, v. 9, ํㅡ 3, ago/dez. 2020 - PPGE - UNESC - ISSN 2317-2452

quem nunca?/ se sou estranha ou esquisita/ como será que você é?/ sou igual, sou diferente/ e você como se sente? ${ }^{9}$

Como encaixar-se nesse mundo? Em um mundo já constituído e cheio de culturas e modos de ser? Um mundo em constante movimento? Esse é o grande desafio de lidar com a pluralidade, pois cada ser humano é único, embora possam ter semelhanças sempre há diferenças. É nesse sentido que Arendt (2007) vai chamar atenção dos/das professores/as que:

[...] na medida em que a criança não tem familiaridade com o mundo, devese introduzi-la aos poucos a ele; na medida em que ela é nova deve-se cuidar para que essa coisa nova chegue à fruição em relação ao mundo como ele é (ARENDT, 2007, p. 239).

Portanto, o exercício da lição deve ser pautado pela responsabilidade ética do/da professor/a que a propõe e pelo princípio da alteridade, do encontrar-se em público e desenvolver a lição. A lição é um exercício de "ler em público, que exige certo ver-se cara a cara, uma presença pública do corpo, um oferecimento público do corpo, às vezes falando e às vezes em silêncio, mas sempre em relação a algo comum" (LARROSA, 2016, p. 143). Nesse sentido, a lição exige um encontro, encontro de pessoas em torno de um objetivo comum. Pode-se dizer que a lição é o espaço de encontro das singularidades/diferenças em torno daquilo que é comum/igualitário, pois ler com outros requer "expor os signos no heterogêneo, multiplicar suas ressonâncias, pluralizar seus sentidos" (LARROSA, 2016, p. 143).

É importante percebermos que na lição existe a necessidade do discurso, isto é, da linguagem. Não basta a presença do Outro, só o encontro físico (corporal) não é potente o suficiente para haver aprendizado.

Abordar Outrem no discurso é acolher sua expressão onde ele ultrapassa em cada instante a ideia que dele tiraria um pensamento. É, pois, receber de Outrem para além da capacidade do Eu; o que significa exatamente: ter a ideia do infinito. A relação com Outrem ou o Discurso é uma relação nãoalérgica, uma relação ética, mas o discurso é um ensinamento. $O$ ensinamento não se reduz, porém a maiêutica. [...] substitui já a maiêutica por uma ação transitiva do mestre, dado que a razão, sem abdicar, se acha na situação de receber (LEVINAS, 2011, p. 38-39 - grifos do autor).

\footnotetext{
${ }^{9}$ Letra de Bruno Gadiol. Música, Igual Diferente, Igual Diferente. Interpretada por Guto e Benê Malhação "Viva a diferença". Disponível: https://www.youtube.com/watch?v=ExPdCADFcgM acesso em 27 de jul. 2020.
} 
Pode-se dizer, então, que no exercício da lição existe a necessidade de acolher aquele que fala (o Outro) e aquilo (o Conteúdo) que ele diz. É, portanto, receber do Outro a ideia do infinito (pois, conhecer o Outro é reconhecer uma infinidade de modos de pensar e de reconhecer o mundo e a si mesmo) e apostar em novos conhecimentos que rompam com opiniões discriminatórias e excludentes. Esse recebimento é próprio da tarefa educativa: aprender um ensinamento que previne a inumanidade, isto demanda perceber o fio de igualdade humana que nos une mesmo na diversidade. Na lição é possível construir uma comunidade de conhecimento.

É possível ainda avançar um pouco mais nessa reflexão e afirmar, assim como Larrosa (2016), que o exercício da lição estabelece laços de amizade entre o grupo que à prática, pois dar resposta às inquietações propostas pela lição é "encarregar-se de algo comum e constituir uma comunidade que não é a do consenso, mas sim da amizade" (LARROSA, 2016, p. 144). Uma relação de amizade que se estabelece na liberdade, que extrapola identidades, entre aqueles que exercitam a lição de modo que "a amizade da leitura não está em olhar um para o Outro, mas em olhar todos na mesma direção e em ver coisas diferentes. A liberdade da leitura está em ver o que não foi visto nem previsto. E em dizê-lo" (LARROSA, 2016, p. 145).

Podemos considerar também o exercício da lição como algo conservador, como algo que talvez já esteja ultrapassado, mas a lição é um exercício que permite olhar para aquilo que já foi produzido e avançar, suspender e profanar. Nesse ponto Arendt (2007) afirma "[...] exatamente em benefício daquilo que é novo e revolucionário em cada criança é que a educação precisa ser conservadora; ela deve preservar essa novidade e introduzi-la como algo novo em um mundo velho" (p. 243). Vale lembrar que a novidade pode surgir da singularidade de cada ser, e pode se expressar na pluralidade, no conjunto de seres que se reúnem em torno da lição.

Para que haja possibilidade de novidade, é fundamental que nos perguntemos "[...] como eles podem renovar o mundo - como eles podem experimentar a 'inovação' - se ninguém realmente os apresenta ao velho mundo e 
Criar Educação, Criciúma, v. 9, № 3, ago/dez. 2020 - PPGE - UNESC - ISSN 2317-2452

traz o mundo antigo para a vida?" (MASSCHELEIN, SIMONS, 2017, p. 102). Por isso a lição é tão importante, pois "[...] ensinar a ler é produzir esse deixar escrever, a possibilidade de novas palavras, de palavras não pré-escritas" (LARROSA, 2016, p. 146). Desse modo, a partir da leitura e do diálogo que se estabelece em torno do que é comum pode ser gerada a novidade.

Para que a educação conserve a novidade inerente a cada sujeito, o/a professor/a possui pelo menos duas tarefas. A primeira diz respeito a libertar a criança de todas as habilidades que atribuem uma função imediata, explicação ou destino para o que essa criança faz (MASSCHELEIN, SIMONS 2017), ou seja, cabe ao/ professor/a permitir que o/a aluno/a esqueça os planos e expectativas dos pais, ou do mercado de trabalho, e mergulhe naquilo que está aprendendo, na lição. Isto significa abrir o mundo e "suspender a questão da utilidade ou valor, e eliminar intenções egoístas de qualquer pessoa para com os alunos" (MASSCHELEIN, SIMONS, 2017, p. 101), deixar que os alunos espontaneamente, a partir do que já estudou, insira-se no mundo comum.

A segunda tarefa, consiste basicamente em estimular o interesse. Vejamos:

A responsabilidade pedagógica não reside em mirar diretamente na (nas necessidades da) criança ou o aluno, mas nas coisas e na sua relação com as coisas, isto é, a relação que o professor como pedagogo tem para com essas coisas. A forma de um professor lidar com, dar forma concreta a, e incorporar coisas e práticas é o que mostra o que é valioso e "autorizado" para ele. Só então o professor pode se comunicar e compartilhar o mundo de uma maneira tal que as crianças e os jovens se tornem interessados e engajados, só então as coisas adquirem autoridade e só então o mundo se torna interessante. [...] Só se pode criar interesse pelo mundo comum mostrando o seu próprio amor por esse mundo (MASSCHELEIN, SIMONS, 2017, p. 102)

Essa tarefa consiste em mostrar como é possível estabelecer inúmeras relações entre o estudado e as coisas e fatos do mundo. Não consiste apenas, portanto, em dizer que isso se relaciona com aquilo de determinado modo. É preciso que o ensino possa ser desenvolvido com maior abertura, mais passível de tentativas, sem restrições a singularidades e a modos de resolver os problemas. Se numa lição se parte para uma leitura que já está interpretada não há possibilidade de interesse. A lição aberta possibilita registrar aquilo que é novo, mesmo que seja um conceito que ganha um novo sentido, mas desperta o interesse. Para que isso 
Criar Educação, Criciúma, v. 9, № 3, ago/dez. 2020 - PPGE - UNESC - ISSN 2317-2452

ocorra é necessário que o/a professor/a mostre o seu amor, o seu interesse, a sua responsabilidade pelo mundo comum.

Por isso atuar como professor/a significa assumir um tipo de responsabilidade ética pela dinamicidade do mundo, pois "a educação é o ponto em que decidimos se amamos o mundo o bastante para assumirmos a responsabilidade por ele e, com tal gesto, salvá-lo da ruína que seria inevitável não fosse a renovação e a vinda dos novos e dos jovens" (ARENDT, 2007, p. 247). Do mesmo modo, é onde decidimos se amamos as futuras gerações e estamos dispostos a não expulsá-las do mundo adulto, instruindo-as na direção da revelação de suas identidades.

\section{Considerações finais}

Ao tratarmos da escola, nesse texto, a tomamos como espaço heterogêneo de relações: como um lugar de transmissão/desenvolvimento de conhecimentos produzidos historicamente pela humanidade, mas também como um lugar de encontro de pessoas que compartilham igualdade e diferença. Se trata, portanto, de um espaço em que jovens e crianças são abastecidos/as com a tradição histórica dos saberes e das práticas e buscam encontrar o seu modo de inserção no mundo comum.

Essa compreensão de escola traz alguns desafios a serem considerados: primeiramente o desafio que o/a professor/a possui de assumir a responsabilidade pedagógica de oferecer o mundo do conhecimento às futuras gerações que estão na escola, de modo não-totalizante e não-autoritário. Essa abertura do e para o mundo acontece quando o/a professor/a coloca um conteúdo sobre a mesa e desafia seus alunos e suas alunas a pensar possíveis relações existentes entre diferentes conhecimentos. Se trata, pois, do desafio de partilhar as diferenças e construir outros modos de ler/estudar aquilo que se conhece.

Outro desafio diz respeito à compreensão da escola como um lugar de experimentação e ensaio. Pergunta-se, a partir da aposta ética-fenomenológica, se na escola não houver abertura para a revelação da identidade, onde haverá? A escola pode ser um espaço de revelação da identidade através dos discursos 
Criar Educação, Criciúma, v. 9, № 3, ago/dez. 2020 - PPGE - UNESC - ISSN 2317-2452

proferidos no exercício da lição, em que se garanta a possibilidade de inserir-se no mundo.

Reitera-se que a convivência e o desenvolvimento de atividades que promovam o respeito à pluralidade humana são elementos importantes a ser observados e considerados durante o processo educativo escolar, pois faz parte da responsabilidade que o/a professor/a assume pelo mundo. A lição, leitura e comentário de um texto, que possibilita o posicionamento de cada sujeito pode ser um exercício de alteridade e de abertura para a novidade, pois permite a revelação da identidade. Desse modo, é possível percebê-lo como uma prática escolar que exerce um papel interessante no campo da alteridade.

\section{Referências}

ARENDT, Hannah. Reflexões sobre Little Rock. In: Arendt, Hannah.

Responsabilidade e julgamento. São Paulo: Companhia das Letras, 2004.

. Entre passado e Futuro. São Paulo: Perspectiva, 2007.

. A condição Humana. Rio de Janeiro: Forense Universitária, 2008.

FOLSCHEID. Dominique; WUNENBURGER. Jean-Jacques. Metodologia filosófica. São Paulo: Martins Fontes, 2006.

LARROSA, Jorge. A lição. In: LARROSA, Jorge. Pedagogia Profana: danças, piruetas e mascaradas. Belo Horizonte: Autêntica Editora, 2016.

MASSCHELEIN, Jan; SIMONS, Maarten. Em defesa da escola: uma questão pública. Belo Horizonte: Autêntica Editora, 2017. $2^{2}$ edição. 